Gut, 1965, 6, 29

\title{
Congenital chloridorrhoea or so-called congenital alkalosis with diarrhoea
}

\author{
J. M. EVANSON AND S. W. STANBURY \\ From the University Department of Medicine and Wellcome Metabolic Ward, \\ Manchester Royal Infirmary
}

EDITORIAL SYNOPSIS Observations are described in an 8-year-old boy, the fifth case to be recognized of the syndrome previously known as 'congenital alkalosis with diarrhoea'. The condition appears to result from an abnormal handling of chloride ion in the alimentary tract; the pathognomic biochemical features are an invariably high faecal concentration of chloride and liquid stools which consistently contain an excess of chloride over the sum of sodium and potassium. Unabsorbed chloride appears to act as an osmotic cathartic and potassium is lost in the resulting watery diarrhoea; the metabolic alkalosis is an acquired consequence of potassium and chloride deficiency. For these reasons, it is suggested that the alternative name of 'congenital chloridorrhoea' provides a more appropriate description of the condition. It appears that the principal aim of therapy should be to correct the potassium deficiency, and experience with the present patient suggests that this might best be achieved by limiting the intake of chloride and, despite the presence of a metabolic alkalosis, giving potassium as an alkaline salt.

Severe diarrhoea is commonly associated with metabolic acidosis, attributed to the loss in the stools of alkaline intestinal contents or of secretions containing proportionately less chloride and more bicarbonate than the blood plasma (Beisel, Watten, Blackwell, Benyajati, and Phillips 1963). Exceptionally, a patient with either acute (Maizels and McArthur, 1929, 1930) or chronic diarrhoea (Lubran and McAllen, 1951; Schwartz, and Relman 1953; de Graeff and Schuurs, 1960; Aber, Sampson, Whitehead, and Brooke, 1962) is found to have a metabolic alkalosis apparently caused by the development of potassium deficiency; but the few such cases that have been studied in detail (Schwartz and Relman, 1953; de Graeff and Schuurs, 1960) showed nothing distinctive about the chemical composition of the stools. Gamble, Fahey, Appleton, and MacLachlan (1945) and Darrow (1945) described simultaneously a new and apparently distinct syndrome in which watery diarrhoea was present from or developed soon after birth; only two similar cases have been reported subsequentiy (Kelsey, 1954; Duyck, 1955). In all the children affected there was a metabolic alkalosis and the liquid faeces differed from those of ordinary infantile diarrhoea (Darrow, Pratt, Flett, Gamble, and Weise, 1949) in consistently containing an excess of chloride over the sum of sodium and potassium. The urine contained virtually no chloride, so that all the excreted chloride was in the faeces; and, especially in the patients of Gamble and of Duyck, it was repeatedly demonstrated that chloride, given orally as the sodium, potassium, or ammonium salt or even administered intravenously as sodium chloride, was recovered almost quantitatively in the stools.

This report describes observations on a fifth case of this syndrome in a boy aged 8 years. The evidence accumulated indicates that the metabolic alkalosis is not primary but caused by potassium and chloride deficiency and that this and the diarrhoea are secondary to an abnormal handling of chloride ion in the alimentary tract. It thus appears that the original description "congenital alkalosis with diarrhoea' (Gamble) may be inappropriate; for reasons that will emerge in the course of description, we prefer to call the condition 'congenital chloridorrhoea' or chloride diarrhoea. This is an abbreviated account of our investigations and is concerned with clinical and therapeutic aspects and with the metabolism of chloride and potassium. A more detailed consideration of the many physiological implications of our results, with an account of observations in other types of diarrhoea, is in preparation (Stanbury and Evanson, 1964). 


\section{THE PATIENT AND THE INVESTIGATION}

M.S. was the second child of healthy, unrelated and Rhesus-compatible parents. His only two siblings, both brothers, had suffered with diarrhoea from birth and both died in infancy from its effects. Although the evidence suggested strongly that all three children were affected with the same disorder (Stanbury and Evanson, 1964), preliminary observations have so far failed to detect any abnormality in either parent.

Labour was induced at the 36th week because of acute hydramnios and the weight at birth was $6.8 \mathrm{lb} .(3.1 \mathrm{~kg}$.). The child had a hare lip and cleft soft palate and he developed intense neonatal jaundice (serum bilirubin, $16.5 \mathrm{mg}$. per $100 \mathrm{ml}$. on the tenth day). The latter had faded by the $21 \mathrm{st}$ day and he weighed $6.5 \mathrm{lb}$. $(2.95 \mathrm{~kg}$.) on leaving hospital at 33 days of age. Subsequently, his mother has never known the child to produce a formed stool but the diarrhoea was not noticed in the neonatal period. The hospital records at that time refer only to 'loose stools' on several occasions and to a 'rather dehydrated appearance'. He was again admitted to hospital at the age of $8 \frac{1}{2}$ months with vomiting and diarrhoea involving the production of up to 10 watery stools per day. Throughout the period before this admission, the stools were loose and there had been periodic attacks of more severe diarrhoea with vomiting. He remained in hospital for eight months. The stools were always loose and there were recurrent bouts of severe watery diarrhoea with vomiting, pyrexia, and dehydration necessitating therapy with parenteral saline fluids. Proteinuria was detected on several occasions, and depending on the state of dehydration, the blood urea varied from 25 to $100 \mathrm{mg}$. per $100 \mathrm{ml}$. Amino-acid chromatography of the urine was normal. On leaving hospital at the age of 16 months, the child weighed 20.9 lb. $(9 \cdot 5 \mathrm{~kg}$.).

The child had to be re-admitted on several occasions and, by the age of 8 years, it was calculated that he had spent one quarter of his life in hospital. At the age of $2 \frac{1}{2}$ years, when admitted to the Duchess of York Hospital, Manchester, he was extremely ill and profoundly dehydrated. He had a significant metabolic alkalosis with low plasma levels of chloride and potassium, and the diagnosis of 'congenital alkalosis with diarrhoea' was made by Dr. Sylvia K. Guthrie. This diagnosis was confirmed in 1963 by Dr. G. M. Komrower who kindly transferred the patient to us for study. On the many occasions that the boy was in hospital, the alimentary tract was intensively investigated by conventional techniques. Bacteriological examination of the stools, determination of faecal fat, d-xylose absorption tests, repeated intestinal radiography, liver function tests, sigmoidoscopy and rectal biopsy, had all produced negative results.

On admission to the Wellcome Metabolic Ward, he was producing 10 to 14 watery stools per day but complained only of the discomfort of peri-anal excoriation. He was an extremely intelligent child of normal slim build (weight $60.5 \mathrm{lb}$.; $27.5 \mathrm{~kg}$.) and normal height (53.2 in.; $135 \mathrm{~cm}$.) and with a normal blood pressure $(100 / 65$ $\mathrm{mm}$. $\mathrm{Hg}$ ). On standing, the stools separated into an amorphous deposit containing occasional food particles and a supernatant, brown, watery liquid. The transit time of a carmine marker was 18 hours. Arterialized venous plasma showed a raised plasma bicarbonate level (total $\mathrm{CO}_{2}, 34-36 \mathrm{~m}$.-mole per litre), a moderately reduced plasma chloride level (88-93 mEq. per litre), and a subnormal plasma potassium level (2.8-3.3 mEq. per litre). The $p \mathrm{H}$ of capillary blood was normal (7·37-7.41) and the arterial $\mathrm{PCO}_{2}$ was raised $(49-54 \mathrm{~mm}$. $\mathrm{Hg}$ ). (In this single respect the patient differed from the four other reported patients, in whom the metabolic alkalosis was uncompensated and the $\mathrm{pCO}_{2}$ low. Conceivably this difference is related to the younger age of the other patients.) The plasma urea concentration was somewhat raised (76 mg. per $100 \mathrm{ml}$., falling to $48 \mathrm{mg}$. per $100 \mathrm{ml}$.) and the inulin clearance, measured after incomplete correction of electrolyte deficiencies, was $49 \mathrm{ml}$. per min. (or $78 \mathrm{ml}$. per min. per $1.73 \mathrm{sq}$. metres). There was no proteinuria and the osmolality of 24-hour urinary specimens reached 465 m.-osmole per kilogram. Paradoxical aciduria (urinary $p \mathrm{H}, 5 \cdot 7-6.4$ ) in the presence of metabolic alkalosis and a low urinary citrate, was reversed after correction of potassium deficiency.

Treatment consisted only in the dietary adjustments described subsequently and the provision of supplementary potassium bicarbonate (up to $45 \mathrm{mEq}$. or $4.5 \mathrm{~g}$. per day). The resulting correction of electrolyte deficiencies produced considerable improvement in apparent well-being, and, although the boy continued to have watery diarrhoea, the frequency of defaecation was reduced to two to five times daily. He gained $2 \cdot 2 \mathrm{lb}$. $(1.0 \mathrm{~kg}$.) in weight and, in the two months after leaving hospital, his height increased by 0.5 in. $(1.25 \mathrm{~cm}$.).

\section{METHODS}

The patient was studied by the conventional metabolic techniques established in this laboratory (Stanbury and Lumb, 1962), urine and faeces being collected in 24-hour aliquots. Faeces were passed directly into weighed homogenizers, which were stored at $0^{\circ} \mathrm{C}$. until each day's collection was completed. Each collection was then homogenized with the minimal addition of water; samples of whole homogenate were submitted to various analyses and other samples were centrifuged and similar analyses made on the supernatant fluid. From these data and the faecal dried weight the concentration of solutes in faecal water was derived.

Data are grouped to correspond with three periods of metabolic study, of which periods 1 and 2 followed consecutively during the first admission while the third period relates to a second admission to hospital three months later. In period 1 the patient was seriously deficient in potassium, sodium, and chloride; during period 2 these deficiencies were largely corrected; and in period 3 the patient was apparently replete with electrolytes and we observed the effects of adding chloride salts to the diet. Data on dietary composition are included in Tables I and II.

It should be noted that, throughout the present description, the term 'intestinal net absorption' of a substance refers simply to the amount taken by mouth minus the amount recovered in the faeces. 
RESULTS

BIOCHEMICAL INDIVIDUALITY OF THE DIARRHOEA Figure 1 relates the concentration of chloride in faecal water to the sum of the concentrations of sodium and potassium in the same specimens. Included are data from 43 daily stool collections in the patient, with comparable data from the four other cases of this syndrome previously reported and from a variety of other types of diarrhoea. In cholera, infantile gastroenteritis, ulcerative colitis, ileostomy fluid, and in watery diarrhoea caused by addiction to laxatives, the sum of concentrations of sodium and potassium invariably exceeded that of chloride. Similar data from patients with watery diarrhoea due to the carcinoid syndrome (Stanbury and Evanson, 1964) and to an islet cell tumour of the pancreas (Espiner and Beaven, 1962) have been omitted from Fig. 1 but, in each case, the figures fell below the line of equivalence. In contrast, in our own patient and in the other four cases of the same syndrome, the concentration of chloride exceeded or equalled that of sodium and potassium. The pattern of loss of monovalent electrolytes in this syndrome thus appears to be unique, and Fig. 1 shows clearly that our own patient closely resembled the other four cases in this respect.

CONCENTRATION OF CHLORIDE IN FAECAL WATER The concentrations of sodium, chloride, potassium, total carbon dioxide, and ammonia in the individual 24-hour collections of faeces, and the range of values for the weight and $\mathrm{pH}$ of these specimens during the three periods of metabolic study, are shown in Figure 2. (Data for the concentrations of calcium, magnesium, phosphate, total osmotically active solutes, 'organic acids', and total solids are omitted in the interests of clarity and brevity. Except for the total solids, which were always low, and for 'organic acids' in the first metabolic period, all were within the range of values found in the water phase of normal stools (Wrong, Morrison, and Hurst, 1961).)

The outstanding feature is the extraordinarily high concentration of chloride, which averaged more than $150 \mathrm{mEq}$. per litre or some $50 \%$ above the concentration of chloride in the plasma. This concentration was independent of the severity of the diarrhoea, there being no correlation between the weights and chloride concentrations of individual faecal collections (see Fig. 2). The faecal chloride concentration was essentially the same during the consumption of two totally different diets of differing chloride content (periods 1 and 2); it remained similarly constant in casual faecal specimens collected subsequently when the boy was an out-
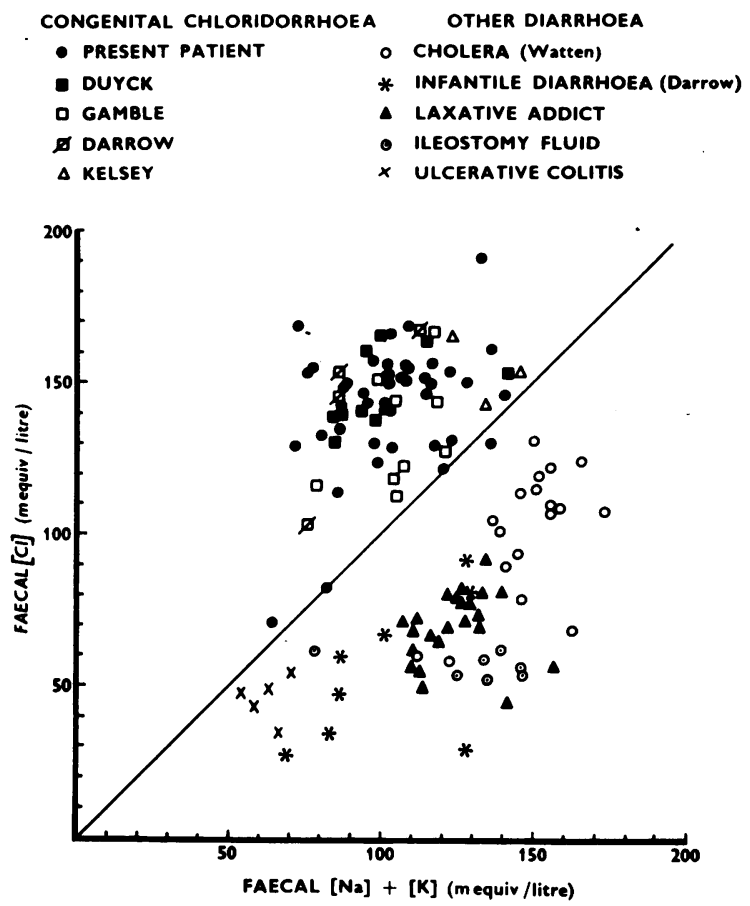

FIG. 1. The relationship of the concentration of chloride to the sum of concentration of sodium and potassium in the faeces. Data from the patient and from other cases of diarrhoea. The oblique line represents equivalence of the two plotted variables.

patient, as well as throughout period 3 when sodium and ammonium chlorides were added deliberately to the diet (Fig. 2). There was no indication that change in the plasma concentration of chloride (which varied from $88 \mathrm{mEq}$. per litre in period 1 to $106 \mathrm{mEq}$. per litre in period 3) produced corresponding changes in the faecal concentration.

It was evident that the high faecal concentration of chloride was not attributable either to the metabolic alkalosis or to potassium deficiency. The retention of potassium and chloride during period 2 (see below) was followed by correction of the metabolic alkalosis, and, during the subsequent three months of continued therapy with potassium bicarbonate, the total carbon dioxide content of arterialized venous plasma remained between 29 and 31 m.-mole per litre but the faecal chloride concentration was persistently high (see period 3, Fig. 2). Similarly, the very high faecal $p H$ and ammonia content during the first metabolic period (Fig. 2) suggested the possibility that the faecal loss of anionic chloride was related to the high output of the cation, ammonium: but, after correction of the electrolyte deficiencies (period 3, Fig. 2), the 


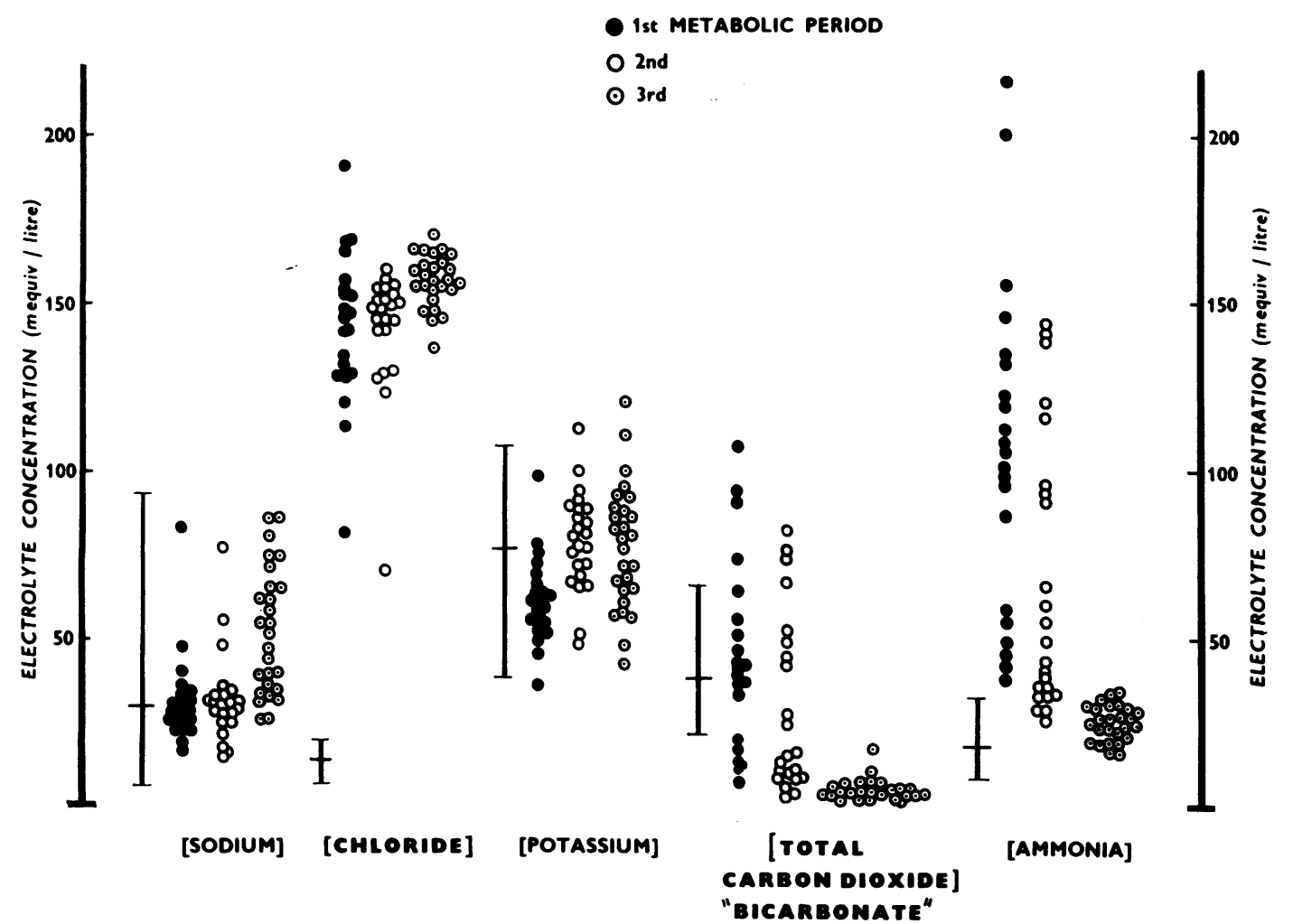

1st metabolic period: faecal weight, $\bar{m}, 570$ g./day (S.D. 182 g./day); faecal $p H, \bar{m}, 8.01$ (S.D. 0.70)

2nd metabolic period: faecal weight, $\bar{m}, 274$ g./day (S.D. 133 g./day); faecal pH, $\bar{m}, 7 \cdot 39$ (S.D. 0.91)

3rd metabolic period: faecal weight, $\bar{m}, 403 \mathrm{~g} . /$ day

(S.D. 191 g./day); faecal pH, $\bar{m} .6 \cdot 17$ (S.D. 0.32)

FIG. 2. The concentration of individual electrolytes in the 24-hour faecal collections from the patient. Data from the three periods of metabolic study are charted separately. The vertical line with cross bar to the left of each set of points shows the range and average values for the concentration of that electrolyte in the water phase of normal faeces (Wrong et al., 1961).

concentration of ammonia in faecal water was within the range found in normal faeces and the faecal $p \mathrm{H}$ fell to levels below the normal without significant change in chloride concentration.

The primary defect thus appeared to involve the mechanisms that normally reduce the chloride concentration of distal colonic and rectal contents to very low levels (7-20 mEq. per litre, Wrong et al. (1961); see Fig. 2). Since the faecal concentration of potassium was within the range normally found in faecal water and the concentration of sodium was at the lower range of normal (periods 1 and 2, Fig. 2), it appears that the colonic functions of potassium secretion and of sodium conservation by active absorption were intact. In spite of this normal behaviour towards cations, it is obvious that the colon is failing to absorb chloride. In the absence of information concerning the electrolytic composition of more proximal intestinal contents, it remains uncertain whether chloride absorption in the ileum is also defective.

CHLORIDE AS AN OSMOTIC CATHARTIC With an effectively constant concentration of chloride in the faecal water (Fig. 2), it is inevitable that the volume of diarrhoeic stools produced each day will vary with the total daily output of chloride in the faeces. This is shown in Fig. 3, which relates the daily faecal weight to the output of chloride and also to the independently measured output of total osmotically active solutes in the faeces (periods 1 and 2 only). The close coincidence of the two plotted variables indicates that the chloride ion is the principal solute determining an osmotic catharsis. Except for three individual values between 505 and $580 \mathrm{~m}$.-osmole per $\mathrm{kg}$., the range (300-438 m.-osmole 
per $\mathrm{kg}$.) and mean (375 m.-osmole per $\mathrm{kg}$.) values for the osmolality of the diarrhoeic stools were the same as obtained by Wrong et al. (1961) for the water phase of normal faeces (range 330-428, mean $376 \mathrm{~m}$.-osmole per $\mathrm{kg}$.). It thus appeared that the bulk of fluid in the colon may have been reduced by absorption of water until the concentration of chloride reached the ceiling of osmolality characteristic of distal colonic contents. The diarrhoea was solely dependent on the failure of chloride absorption.

THERAPEUTIC EFFECTS OF RESTRICTING DIETARY CHLORIDE The relationship shown in Fig. 3 and the earlier observation that giving additional chloride might increase both the faecal output of chloride and the severity of the diarrhoea (Gamble et al., 1945; Duyck, 1955) suggested that a reasonable therapy for the syndrome would be to reduce the dietary intake of chloride rather than increase it as has previously been recommended.

Although the boy received a constant diet from the time of admission to hospital, for the first 36 hours he had access to table salt which he added to his food in the large amounts previously recommended. After withdrawal of salt, he received only the diet containing $76 \mathrm{mEq}$. of chloride for 15 days (period 1) when he was transferred to the second diet containing $47 \mathrm{mEq}$. of chloride (period 2). Figure 4 shows the effects of these changes in chloride intake on the daily weight of faeces excreted and it is evident that restriction of chloride intake reduced the severity of the diarrhoea. During period 2 defaecation became less frequent, the peri-anal excoriation healed, and the water content of the stools fell to a mean value of $92.28 \mathrm{~g} . / 100 \mathrm{~g}$. (S.D. 1.12 g./100 g.) as compared with the value of 94.22 g./100 g. (S.D. 1.31 g./100 g.) during the first period.

Despite this gratifying justification of our therapeutic expectations, it was not clear whether the beneficial effects were attributable directly to the reduced intake of chloride itself or to the concomitant equivalent reduction of sodium intake. In the event, it seems more probable that the principal benefit was attributable to the changes in potassium metabolism caused by the reduced intake of sodium chloride.

POTASSIUM DEFICIENCY AND ITS RELATION TO THE FAECAL AND URINARY OUTPUT OF CHLORIDE Figure 5 shows that the faecal output of potassium (and of sodium) varied with the faecal output of chloride. During the first metabolic period, the output of chloride in the faeces was the same as the amount ingested (Table I); the urine contained no chloride.

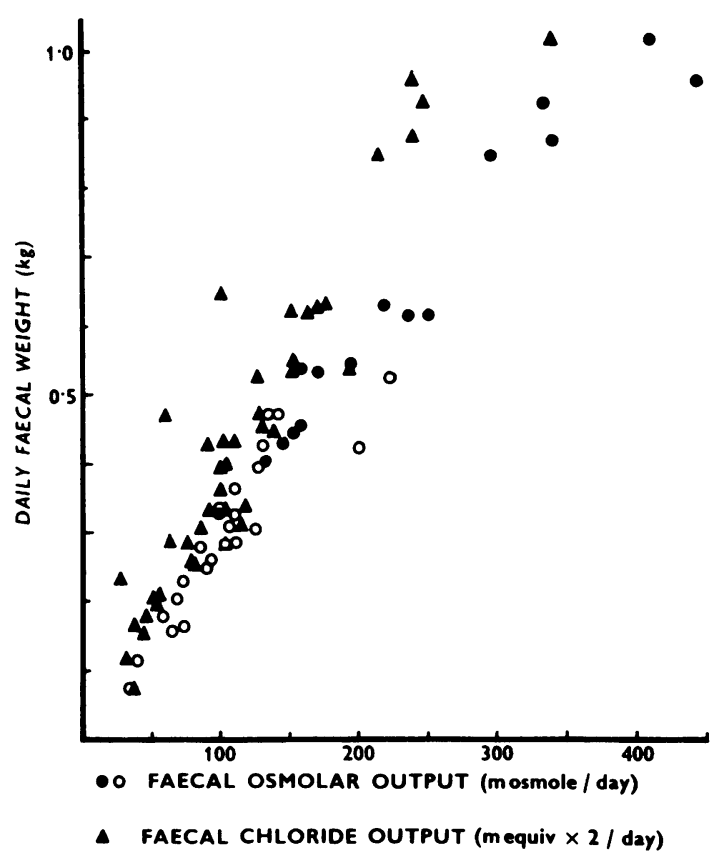

FIG. 3. The relationship of the faecal weight to the daily outputs of chloride and total osmotically active solutes in the faeces.

Although we do not know how much table salt the patient ate during his first two days in hospital, he excreted no chloride in the urine and the much higher faecal output of chloride at that time $(213,165$, and $107 \mathrm{mEq}$. respectively on days 1,2 , and 3 ; compare the corresponding faecal volumes in Fig. 4) suggests that the faecal excretion of chloride was varying with the intake of sodium chloride, as described in their patients by Gamble et al. (1945) and Duyck (1955).

When the patient was transferred to the diet of lower chloride content (period 2), the faecal loss of potassium was correspondingly reduced (Fig. 5) and in consequence he went strongly into positive potassium balance (Table I). Simultaneously and unexpectedly, the faecal output of chloride fell well below the level of intake (Fig. 5 and Table I): for the first time we observed an intestinal net absorption of chloride which was sustained throughout the period of observation. Presumably because the patient was deficient in chloride, none of the absorbed chloride was excreted in the urine and the cumulative retention during period 2 was $237 \mathrm{mEq}$. The cumulative retention of sodium during the 26 days of metabolic study was $297 \mathrm{mEq}$. and of potassium, corrected for retention of nitrogen, was $404 \mathrm{mEq}$. The combined retention of potassium and 


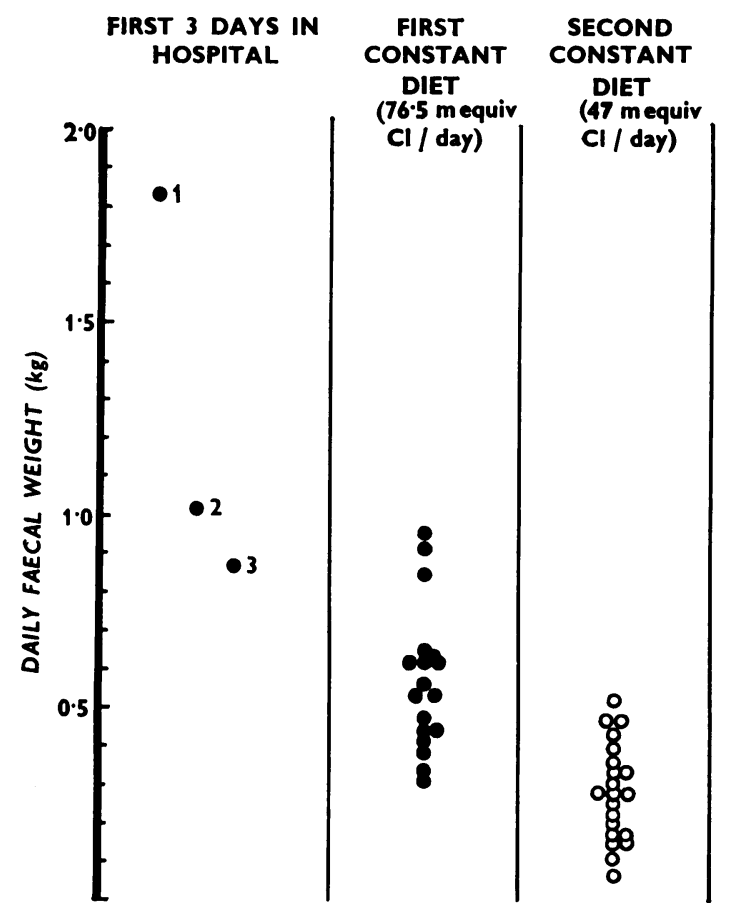

FIG. 4. The effects of changes of chloride intake on the daily weight of the stools (periods 1 and 2, see text). On each of the two diets the variation in daily faecal weight was random.

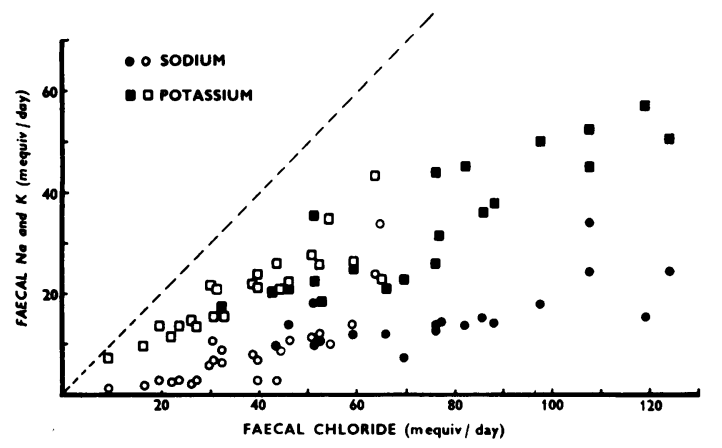

FIG. 5. The relationship between the daily output of chloride and the daily outputs of sodium and potassium in the faeces (periods 1 and 2). Note that in the second metabolic period (open symbols) the daily output of chloride was usually much less than the $47 \mathrm{mEq}$. taken in the diet.

chloride was accompanied by correction of the extracellular alkalosis and the plasma potassium increased to $4 \mathrm{mEq}$. per litre.

One is faced with the paradox that a reduction in the dietary intake of chloride during period 2 actually facilitated its intestinal absorption and bodily retention. Since the intake of sodium was reduced simultaneously (Table $\mathrm{I}$ ), this effect might be explained by an increased secretion of aldosterone causing increased salt absorption in the small intestine, in the same way that administration of mineralocorticoids will reduce the delivery of sodium to an ileostomy (Goulston, Harrison, and Skyring, 1963). Results obtained during the third period of metabolic study suggest that this is probably an incomplete explanation of the paradox. These observations are summarized in Fig. 6 and Table II, which are largely self explanatory; the salient features are as follows. When the daily intake of chloride was increased to about $100 \mathrm{mEq}$. by giving an oral supplement of either the ammonium (period 3B, Fig. 6) or sodium (period 3C) salt, there was an intestinal net absorption of $25 \mathrm{mEq}$. of chloride per day (Table II), and the faecal output of chloride was less than it had been in period 1 (Table I) during which the chloride intake had been lower ( $76.5 \mathrm{mEq}$. per day). Increasing the ratio of sodium to potassium in the dietary intake without changing the intake of chloride (periods $3 \mathrm{C}, 3 \mathrm{D}$, Fig. 6), produced detectable increases in the faecal output of chloride (Table II) but these changes were small and of doubtful significance. As is discussed subsequently, there are reasons to believe that the

\section{TABLE I}

METABOLIC EFFECTS OF RESTRICTING DIETARY INTAKE OF CHLORIDE

\begin{tabular}{|c|c|c|c|c|c|c|}
\hline \multirow[t]{2}{*}{$m E q . / d a y$} & \multicolumn{3}{|c|}{ Period I (15 days) } & \multicolumn{3}{|c|}{ Period 2 (2I days) } \\
\hline & $\mathrm{Cl}$ & $K$ & $\mathrm{Na}$ & $\mathrm{Cl}$ & $\boldsymbol{K}$ & $\mathrm{Na}$ \\
\hline $\begin{array}{l}\text { Mean dietary intake } \\
\text { Mean faecal output } \\
\text { Mean daily retention }\end{array}$ & $\begin{array}{l}76 \cdot 5 \\
76 \cdot 4 \\
\text { Nil }\end{array}$ & $\begin{array}{r}103 \\
32 \cdot 1 \\
6.6\end{array}$ & $\begin{array}{r}74.5 \\
13.8 \\
9.1\end{array}$ & $\begin{array}{l}47.2 \\
35 \cdot 1 \\
11.5\end{array}$ & $\begin{array}{l}86 \cdot 1 \\
19.5 \\
14 \cdot 5\end{array}$ & $\begin{array}{r}47 \cdot 7 \\
8 \cdot 6 \\
7 \cdot 6\end{array}$ \\
\hline
\end{tabular}

The figures for potassium retention have been corrected for retention of nitrogen.

\section{TABLE II}

EFFECTS OF VARYING INTAKES OF CHLORIDE, SODIUM, AND POTASSIUM ON THE FAECAL AND URINARY OUTPUTS OF CHLORIDE ${ }^{1}$

\begin{tabular}{|c|c|c|c|c|c|}
\hline & \multicolumn{3}{|c|}{$\begin{array}{l}\text { Total Intake } \\
\text { (mEq./day) }\end{array}$} & \multicolumn{2}{|c|}{$\begin{array}{l}\text { Mean Chloride Output } \\
\text { (mEq./day) }\end{array}$} \\
\hline & $\mathrm{Na}$ & $\boldsymbol{K}$ & $\mathrm{Cl}$ & Faeces & Urine \\
\hline $\begin{array}{l}\text { Period 3A (6 days) } \\
\text { Period 3B (4 days) } \\
\text { Period 3C (5 days) } \\
\text { Period 3D (6 days) } \\
\text { Period 3E (6 days) }\end{array}$ & $\begin{array}{r}51.5 \\
51.5 \\
102.5 \\
102.5 \\
51.5\end{array}$ & $\begin{array}{l}91.8 \\
91.8 \\
91.8 \\
52.7 \\
52.7\end{array}$ & $\begin{array}{r}50.5 \\
97.5 \\
101 \cdot 5 \\
101 \cdot 5 \\
50.5\end{array}$ & $\begin{array}{l}51 \cdot 4 \\
62 \cdot 0 \\
64 \cdot 4 \\
69 \cdot 3 \\
53 \cdot 9\end{array}$ & $\begin{array}{l}1 \cdot 1 \\
4 \cdot 1 \\
33 \cdot 0 \\
22 \cdot 8^{2} \\
13 \cdot 5\end{array}$ \\
\hline
\end{tabular}

${ }^{1}$ After the correction of electrolyte deficiencies; period 3.

${ }^{2}$ The abrupt fall in urinary chloride at the beginning of period 3D (see Fig. 6) was not due to a reduction of its intestinal net absorption. It was accompanied by a commensurate fall in urinary sodium and appeared to be a direct consequence of reducing the intake of potassium bicarbonate. 

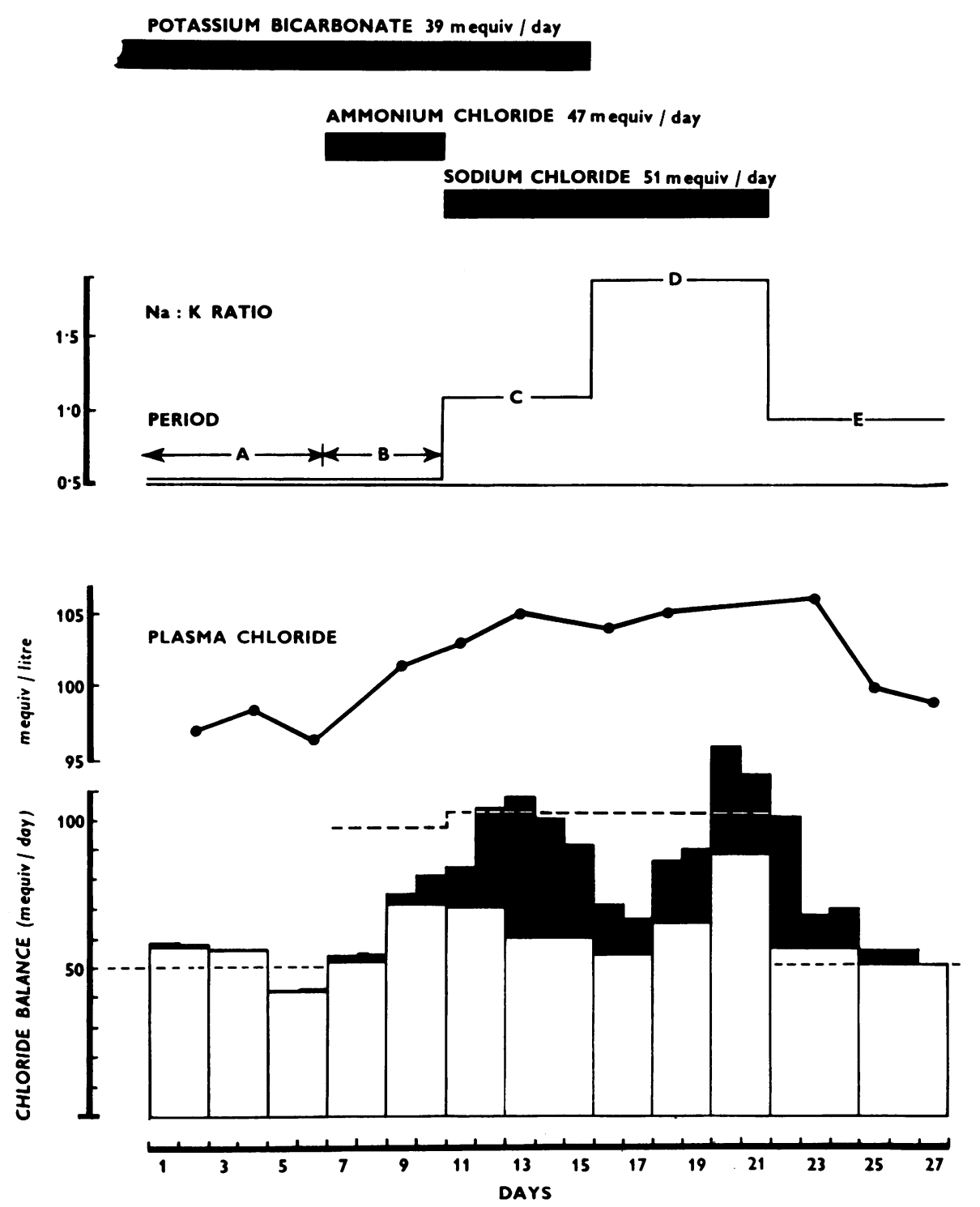

FIG. 6. Effects of changes in the intake of $\mathrm{Cl}$ and $\mathrm{Na}: \mathrm{K}$ ratio of ingested food and salts on the external chloride balances (period 3). In the columns of metabolic data below, faeces are shown in white, urine in black; the level of intake is indicated by the interrupted horizontal line. enormous potassium deficiency present was responsible for the complete failure of intestinal net absorption of chloride during period 1 .

It is further to be noted that the net absorption of chloride during period 3 was associated with a progressive rise in the plasma chloride (Fig. 6); and, when this exceeded approximately $100 \mathrm{mEq}$. per litre, chloride was excreted in the urine in increasing amounts. The absence of chloride from the urine throughout period 2 was related to the fact that the plasma chloride at no time exceeded $95 \mathrm{mEq}$. per litre.

It is thus evident that, after correction of his severe deficiency of potassium, the patient no longer exhibited several features of the syndrome as it was originally described. The metabolic alkalosis, the failure of intestinal net absorption of chloride, and the absence of chloride from the urine must be regarded as secondary phenomena; the primary abnormality, the high concentration of chloride in the faecal water, has persisted unchanged (Fig. 2).

ACIDITY OF THE CHLORIDORRHOEIC STOOL The chloridorrhoea has been stressed as the most obviously abnormal biochemical feature of the stools; but, once the complicating electrolyte 
deficiencies were corrected, an equally outstanding feature was the very low bicarbonate content and pH of the faeces (Fig. 2, period 3). During period 3, with daily faecal volumes that reached 500 to $840 \mathrm{ml}$., the total output of carbon dioxide $\left(\mathrm{HCO}_{3}{ }^{-}+\right.$ $\mathrm{H}_{2} \mathrm{CO}_{3}$ ) in the faeces did not exceed 2-4 m.-moles per day. Except in ulcerative colitis, we have seen no other diarrhoea of similar magnitude with so low a faecal content of bicarbonate; while a similar acidity of the stools was noted in the other reported cases of congenital chloridorrhoea. This suggests that the innate defect of the intestinal epithelium may involve the exchange mechanism (Parsons, Powell, and Pyrah, 1952; Annis and Alexander, 1952; d'Agostino, Leadbetter, and Schwartz, 1953) by which absorbed chloride is replaced by secreted bicarbonate. A more detailed analysis of this possibility is outside the scope of the present paper.

\section{DISCUSSION}

It is universally appreciated that a severe acute diarrhoea or a sustained diarrhoea of lesser severity can produce serious bodily deficiencies of sodium, chloride, and potassium; the secondary effects of these deficiencies on renal function have been extensively studied and are equally well known. No systematic study has been made, however, of the possible effects that such deficiencies might have on the secretory and absorptive functions of the intestines or, more simply, on the composition of the diarrhoeic stool itself. In attempting to elucidate the nature of the primary biological defect in the present syndrome, it was necessary to identify and exclude phenomena caused by electrolyte deficiencies. The alkalinity of the stools during period 1 (Fig. 2) and their high concentration of bicarbonate and ammonia appeared to be related to the combined deficiencies of sodium and potassium (Stanbury and Evanson, 1964). After correction of these deficiencies the stool was acidic, containing little bicarbonate and no higher concentration of ammonia than is found in normal faeces (period 3, Fig. 2). After correction of sodium deficiency and during the subsequent administration of additional sodium salts, the faecal concentration of sodium increased by a factor of 2 to 3 (compare periods 1 and 3, Fig. 2). It is also evident, on comparing the first with the two subsequent periods of metabolic study (Tables I and II) that the patient had also altered his response to the administration of chloride by acquiring some capacity for its intestinal net absorption. In attributing this change to the correction of potassium deficiency, we have been influenced by the extreme degree of the patient's deficit, by the temporal relationship of the change to the establishment of a markedly positive balance of potassium, and also by certain evidence available from the literature. Ariel (1954) described a man of 66 years with diverticulitis who developed acute colonic obstruction after suffering intermittently with diarrhoea for a year. A transverse colostomy was performed and intestinal contents were aspirated by Wangensteen tube: because the aspirated fluid was replaced only by 'glucose-saline' given parenterally, the patient developed severe potassium deficiency and extracellular alkalosis. After one week the colostomy discharged a watery fluid which increased in volume as attempts were made to replace the losses by saline infusions. It was shown that the faeces contained twice as much chloride as sodium, that the concentration of chloride exceeded that of sodium plus potassium, and that the faecal output of chloride increased with its intake. The diarrhoea, the abnormal loss of chloride, and the alkalosis were controlled by administration of potassium chloride. Essentially similar experiences in patients with ulcerative colitis and potassium deficiency have been mentioned, although not documented, by Gardner, MacLachlan, Terry, and Butler (1949), Broch (1950), and Fuller Albright (cited by Darrow and Pratt, 1950). It is probably significant that this phenomenon of 'acquired chloridorrhoea' has been recognized only in patients with potassium deficiency complicating the diarrhoea of primary colonic disease. The faecal output of chloride remains normal in patients with gross potassium deficiency caused by renal or adrenal disease and even in patients with diarrhoea due to small intestinal malabsorption who develop potassium deficiency and extracellular alkalosis (Stanbury, unpublished observations). This suggests that a severe deficiency of potassium may so affect the transfer of electrolytes in the small intestine as to cause an increased delivery of chloride to the colon; and, whereas this additional load of chloride may be within the absorptive capacity of the healthy colon (Levitan, Fordtran, Burrows, and Ingelfinger, 1962), a diseased colonic epithelium may fail to absorb it and chloridorrhoea results. While realizing that this is speculative interpretation of the observed phenomena, we suggest tentatively that acquired potassium deficiency in the syndrome here reported causes increased delivery of chloride to a colon (and possibly also distal ileum) with a congenital defect of chloride absorption. This would explain the behaviour of our own patient during period 1, as well as the failure of the intestinal net absorption of chloride in the patients of Gamble et al. (1945) and of Duyck (1955).

A clear distinction must be drawn between the reversible failure of intestinal net absorption just described and the persistently high faecal con- 
centration of chloride that we consider to be pathognomonic of the disease. Although net absorption increased and faecal output fell with correction of potassium deficiency (Tables 1 and II), the concentration of chloride in faecal water was actually somewhat higher than it had been previously (Fig. 2). The osmotic effect of the unabsorbed chloride ion at all times accounted adequately for the watery diarrhoea (Fig. 3) which was in turn chiefly responsible for the development of potassium deficiency. It is our personal experience that the faecal loss of potassium in a case of diarrhoea generally varies with the volume of the stool (Stanbury and Evanson, 1964) as it did also in the present patient. The boy also continued to excrete potassium in the urine despite a low level of potassium in the plasma, as was noted in his patient by Kelsey (1954). The responsible renal mechanisms and the related problems of acid-base balance will not be discussed here (Stanbury and Evanson, 1964) but it is probable that urinary loss contributed to the development of potassium deficiency. The effects of potassium deficiency on intestinal function (see above) caused an increased faecal output of chloride with consequent intensification of the diarrhoea and further loss of potassium. There was thus created a vicious circle that was broken in the present patient by limiting the intake of chloride. An apparently primary disorder of chloride metabolism engendered a secondary disturbance involving the same ion; or 'primary chloridorrhoea' was complicated by the 'secondary chloridorrhoea' of potassium deficiency. There is ample evidence that the four other reported cases of this syndrome were also deficient in potassium when under study; and Darrow (1945) fully appreciated the significance of this as the probable cause of the metabolic alkalosis. It is also of interest that, during a three-day period of metabolic study in which he was given supplementary potassium chloride, Darrow's patient retained $77 \mathrm{mEq}$. of potassium, an enormous gain in a child weighing only $6 \cdot 2 \mathrm{~kg}$. The faecal output of chloride fell from $76 \mathrm{mEq}$. on the first day to $16 \mathrm{mEq}$. on the third day and this was the only occasion on which an actual net absorption of chloride was observed; but, if one calculates the concentration of chloride in each daily specimen, it becomes apparent that this did not change $(116,131$, and $121 \mathrm{mEq}$. per litre on days 1,2 , and 3 respectively).

Although rare, this condition may be more common than is suggested by the small number of cases reported. It is significant that both siblings of the present patient died in infancy from the effects of a congenital diarrhoea. Detection of the disorder may involve no more than the simultaneous determination of the faecal chloride, sodium, and potassium; and, since the metabolic alkalosis is not innate but a consequence of acquired potassium deficiency, the condition should be sought in infants with unexplained watery diarrhoea irrespective of the prevailing state of acid-base balance.

The detailed biochemical study of diarrhoeic stools has been singularly neglected: in the course of the present study it became apparent that the development of electrolyte deficiencies may cause secondary changes in the composition of the diarrhoeic stool itself. Several such effects are mentioned and particular attention is directed to the effects of potassium deficiency on the intestinal net absorption of chloride. Through this action, the acquisition of potassium deficiency may be responsible for an intensification of the diarrhoea in various colonic diseases as well as in congenital chloridorrhoea.

\section{ADDENDUM}

Since this paper was submitted for publication, two further cases of the same syndrome have been reported, (Tucker, Wilmore, Kaiser, and Laurer 1964; Owen, 1964). In both cases a deficiency of intestinal lactase was demonstrated but considered to be a non-specific effect of chronic diarrhoea. The first child, aged 13 months, was seriously depleted of potassium; chloride was the principal faecal electrolyte but its concentration (82-89 mEq. per litre) was lower than in other cases. Potassium deficiency was not documented in the child described by Owen; the faecal concentration of chloride was 155-160 mEq. per litre.

\section{REFERENCES}

Aber, G. M., Sampson, P. A., Whitehead, T. P., and Brooke, B. N. (1962). The role of chloride in the correction of alkalosis associated with potassium depletion. Lancet, 2, 1028-1030.

d'Agostino, A., Leadbetter, W. F., and Schwartz, W. B. (1953). Alterations in the ionic composition of isotonic saline solution instilled into the colon. J. clin. Invest., 32, 444-448.

Annis, D., and Alexander, M. K. (1952). Differential absorption of electrolytes from the large bowel in relation to ureterosigmoid anastomosis. Lancet, 2, 603-606.

Ariel, I. M. (1954). Chloridorrhea: syndrome associated with diarrhea and potassium deficiency. Arch. Surg., 68, 105-116.

Beisel, W. R., Watten, R. H., Blackwelı, R. Q., Benyajati, C., and Phillips, R. A. (1963). The role of bicarbonate pathophysiology and therapy in Asiatic cholera. Amer. J. Med., 35, 58-66.

Broch, O. J. (1950). Low potassium alkalosis with acid urine in ulcerative colitis. Scand. J. clin. Lab. Invest., 2, 113-119.

Darrow, D. C. (1945). Congenital alkalosis with diarrhea. J. Pediat., 26, 519-532.

- , and Pratt, E. L. (1950). Fluid therapy: relation to tissue composition and the expenditure of water and electrolyte. J. Amer. med. Ass., 143, 365-373, 432-439.

- 1 , Flett, J., Jr., Gamble, A. H., and Weise, H. F. (1949). Disturbances of water and electrolytes in infantile diarrhea. Pediatrics, 3, 129-156.

Duyck, E. M. R. A. (1955). L'alcalose congénitale avec diarrhée. Thèse. Stenfert Kroese, Leyden. 
Espiner, E. A., and Beaven, D. W. (1962). Non-specific islet-cell tumour of the pancreas with diarrhoea. Quart. J. Med., 31, 447-471.

Gamble, J. L., Fahey, K. R., Appleton, J., and MacLachlan, E. (1945). Congenital alkalosis with diarrhea. J. Pediat., 26, 509-518.

Gardner, L. I., MacLachlan, E. A., Terry, M. L., and Butler, A. M. (1949). Chloride diarrhea and systemic alkalosis in potassium deficiency. Fed. Proc., 8, 201.

Goulston, K., Harrison, D. D., and Skyring, A. P. (1963). Effect of mineralocorticoids on the sodium/potassium ratio of human ileostomy fluid. Lancet, 2, 541-542.

de Graeff, J., and Schuurs, M. A. M. (1960). Severe potassium depletion caused by the abuse of laxatives. Acta. med. scand., 166, 407-422.

Kelsey, W. M. (1954). Congenital alkalosis with diarrhea. Amer. J. dis. Child., 88, 344-347.

Levitan, R., Fordtran, J. S., Burrows, B. A., and Ingelfinger, F. J. (1962). Water and salt absorption in the human colon. J. clin. Invest., 41, 1754-1759.

Lubran, M., and McAllen, P. M. (1951). Potassium deficiency in ulcerative colitis. Quart. J. Med., 20, 221-232.
Maizels, M., and McArthur, C. B. (1929). Acidaemia and alkalaemia in the diarrhoea and vomiting of infants. Ibid., 22, 581-610.

- - (1930). Alkalaemia in the diarrhoea of infants. Ibid., 23, 171-174.

Owen, G. M. (1964). Metabolic alkalosis with diarrhea and chloridefree urine. J. Pediat., 65, 849-857.

Parsons, F. M., Powell, F. J. N., and Pyrah, L. N. (1952). Chemical imbalance following ureterocolic anastomosis. Lancet, 2 , 599-602.

Schwartz, W. B., and Relman, A. S. (1953). Metabolic and renal studies in chronic potassium depletion resulting from overuse of laxatives. J. clin. Invest., 32, 258-271.

Stanbury, S. W., and Evanson, J. M. (1964). to be published.

- , and Lumb, G. A. (1962). Metabolic studies of renal osteodystrophy. I. Calcium, phosphorus and nitrogen metabolism in rickets, osteomalacia and hyperparathyroidism complicating chronic uremia and in the osteomalacia of the adult Fanconi syndrome. Medicine (Baltimore), 41, 1-31.

Tucker, V. L., Wilmore, D., Kaiser, C. J., and Laurer, R. M. (1964). Chronic diarrhea and alkalosis. Pediatrics, 34, 601-608.

Wrong, O. M., Morrison, R. B. I., and Hurst, P. E. (1961). A method of obtaining faecal fluid by in-vivo dialysis. Lancet, 1, 12081209. 